\title{
PSYCHIATRIC EXAMINATION OF PERSONS ACCUSED OF CRIME*
}

\author{
SHELDON GLUECK
}

Again and again we have had our attention drawn to the evil features of the law's treatment of mental disorder in criminal cases. The object of this discussion is to call attention to a very important piece of legislation regarding the psychiatric examination of certain classes of persons accused of crime, the principle of which has for the first time in American legal history been enacted into law.

In spite of the long-standing disagreement between the legal and medical professions on the question of the relationship of mental unsoundness to criminal responsibility and punishability, there is some evidence that the differences between the two professions are giving way before a spirit of intelligent co-operntion. ${ }^{1}$ The conscious attempt scientifically to treat a problem that has long vexed jurists-the determination of the status of the offender who is possibly mentally unsound-is especially manifest in recent Massachusetts legislation, providing for the psychiatric

\footnotetext{
* Read before the section on Economic and Social Problems, American Society for the Advancement of Science, Philadelphia, Dec. 29, 1926.

1 See S. Glueck, A Tentative Program of Co-operation Between Psychiotrists and Lawyers (1925) 9 MENTAL HYGIENE, 686. The fact that practically all of the numerous "crime commissions" which have recently been established are apparently making efforts to give practical study to the rôle of psychiatry in the administration of criminal justice supports tho above contention. Unfortunately, the opposite attitude is still strong, as witness the recent opinion of the Chief Justice of the highest MIassachusotts court in an appealed case in which counsel tried to raise the question of defendant's mental condition at the time of the offense:

"The judge who denied the motion presided over the jury trial, saw the defendant, heard him testify in his own behalf, and of course watched his apparent mental capacity as revealed under direct and cross-examination. and by his other conduct during the trial. The judge may well have been able to form a judgment as to legal responsibility of the defendant for crime, based upon common sense inferences and intelligent observation, more reliable as a practical guide to accomplishment of justice than the refined distinctions and technical niceties of alienists and experts on psychopathic inferiority." Commonwealth v. Devereaux, 153 N. E. 881 , at 882 (MIass. 1926).

To speak of "common sense inferences" with regard to so intricato a problem as a person's mental condition is naive. If a question as to tho specifications, condition, etc., of a bridge or house were involved in litigation an appellate tribunal would hardly leave it to "common sense inferences" of the trial judge, where engineering or building experts disagreed with the judge's inspirational solution of the problem.
} 
examination as a matter of course or routine of certain classes of persons accused of crime.

It should be pointed out that we are not at present discussing the vexing problem of the "plea of insanity," which involves a legal attack upon the prosecution's case, based on the absence, at the time of the alleged offense, of the requisite mental element in the definition of crime.' Indeed, we are rather interested in the possibility of eliminating trials, or at least reducing them to a mere formality, in cases where the Missachusetts procedure about to be described offers a more rational instrument for the solution of the problems involved, from the points of view of the offender and the community, than is presented by the tangled web of legislation and case law that now constitutes the "defense of insanity."

\section{THE MIASSACHUSETTS LAW "IN BOOKS"}

Elsewhere ${ }^{3}$ the old English law and the existing state legisation on the subject of determining the mental condition of accused persons awaiting trial has been described in detail and analyzed. Suffice it to say here that that analysis disclosed a serious weakness in such legislation, namely, that initiation of proceedings for mental examination of persons accused of crime is everywhere, except in Massachusetts, left to persons untrained in psychiatry." In other words, it is largely a pure matter of chance, or of the strategy of the defendant's counsel, as to whether or not the defendant is given a mental examination before or during trial unless his symptoms are strikingly suggestive of the "raving maniac" or the "driveling idiot."

The unique measure passed by the Commonwealth of Massachusetts several years ago ${ }^{5}$ constitutes the most radical step yet taken to provide for the mental examination of accused persons awaiting trial. It is attracting not only local, but European interest. It is the first piece of legislation that aims at maling the mental examination of those indicted for certain classes of crimes a routine matter not dependent upon the expert lnowledge, alertness, desire or caprice of those temporarily in charge of the accused. Theoretically, at least, all pcrsons who fall

2 For a complete discussion of this problem from the points of view of Ethics, Psychology, Psychiatry and Law, see S. Gluecr, MIExtal Disonoen and the Criminat LaW (1925).

${ }^{3}$ See S. Glueck, State Legislation Providing for the Mcntal Ezamination of Persons Accused of Crime (1924) 8 IIENTaL Hygnene, 1.

4 It is extremely doubtful whether even the average jail physician, without special training and experience in psychiatry, is qualified to pass upon the mental condition of detained persons.

5The passage of this pioneer piece of legislation is largely due to the vision and ceaseless efforts of Dr. L. Vernon Briggs of Boston. 
within one of the three categories mentioned by the law must be mentally examined before trial, whether or not they exhibit symptoms of mental abnormality recognizable by the non-expert in mental diseases, $i$. e., the police officer, jail warden, counsel for the defense, prosecuting attorney or judge.

Moreover, when once the psychiatric examination is called for, the Massachusetts law avoids the inefficient or cumbersome procedure and machinery for such examination that exists in other jurisdictions. Thus, in some states, it is left to the discretion of the court how to determine the question of supposed mental unfitness for trial, if that question happens to be raised; in others, the judge, taking such evidence as he may desire, is required to conduct an inquiry into accused's mental condition when the point is properly brought up. In a number of states it is within the judge's discretion whether or not he shall try this preliminary "issue" of the defendant's mental condition at the time of the proposed trial in chief. Some states specifically provide for a jury to pass upon the alleged "insanity" of an accused person who is in confinement under indictment, this preliminary hearing being in the nature of an elaborate technical trial, precisely as if the main issue, the guilt or innocence of the defendant, were being considered. In one state the inquiry may be made by the court, or a commission appointed by it, or a special jury. In a few New England states the court may send the accused to a hospital for observation, if it believes that the technical "defense" of a "plea of insanity" is to be filed in the case; one or two states provide for an inquiry either by two "qualified physicians" or by a commission composed of two physicians and a lawyer. ${ }^{\circ}$

The objections to these types of procedure are plain. Obviously, a jury is unfit to settle a medical question; for it must be remembered that, strictly speaking, we are not at this stage concerned with the question of technical guilt or innocence-a jury problem-but with mental capacity to undergo trial and with the avoidance of a long-drawn, expensive trial where a more sensible disposition of a case can be made. Further, the procedure we are criticizing duplicates a jury trial; since, if the defendant is found by the first jury to be "sane" at the time of such trial, he is tried again, either by the same jury or another, on the main issue of guilt or innocence. Where experts are appointed by the court, it is doubtful in many cases whether they have the proper qualifications in the way of education and experience, unless these are specifically and stringently defined by statute. Besides, all the methods of appointing experts and of

\footnotetext{
G The citations to the statutes mentioned in this paragraph are to be found in GLUECK, op. cit. supra note 2, c. 3. The laws themselves are collected in the appendix thereto.
} 
conducting technical hearings before the court smack too much of a trial on the main issue of guilt or innocence; and the principal object-that of sorting out those defendants on whom the expense and time of a trial would be wasted, and whom it is inhumane to try-would thus seem largely to be defeated.

We shall see, however, that the Mrassachusetts law is easily the most far-sighted piece of legislation yet passed on this subject. This statute went into effect in September, 1921, and has since been twice amended. The law at present provides in part that:

"Whenever a person is indicted by a grand jury for a capital offense or whenever a person, who is known to have been indicted for any other offense more than once or to have been previously convicted of a felony, is indicted by a grand jury or bound over for trial in the superior court, the clerk of the court in which the indictment is returned, or the clerk of the district court or the trial justice, as the case may be, shall give notice to the department of mental diseases, and the department shall cause such person to be examined with a view to determine his mental condition and the existence of any mental disease or defect which would affect his criminal responsibility. The department shall file a report of its investigation with the clerk of the court in which the trial is to be held, and the report shall be accessible to the court, the district attorney, and to the attorney for the accused." ?

In the first place, this act eliminates the objectionable features present in all other state legislation on the subject; that is, the classes of offenders mentioned in the law are examined as a matter of course, the procedure applying to all such offenders. Further, the examinations are made by a ncutral, unbiased agency - the State Department of Miental Diseases-its experts trained and experienced in psychiatry; and the examinations are made before trial, and before it is decided whether or not to resort to the frequently-abused "defense of insanity." Moreover, the examination is not a technicality-ridden procedure, before a judge and in the presence of the district attorney or before a judge and jury, such as in other jurisdictions really amounts to

7 Mass. Acts 1921 , c. 415 , as amended by Mass. Acts 1923 , c. 331 , and Mass. Acts 1925, c. 169, of which the foregoing is an extract. The original law further provided that the report "shall be admissible as evidence of the mental condition of the accused," but was amended to omit this arid provide that "Any clerk of court or trial justice who wilfully neglects to perform any duty imposed upon him by this section shall be punished by a fine of not more than fifty dollars." It is not believed that the change with reference to the admissibility of the report as evidence will militate materially against the effectiveness of this law in actual practice (nor has it done so to date) as the act still leaves great opportunity to the court, prosecutor and defense counsel for obtaining the facts in an unbiased manner to guide them in their subsequent procedure with the case. 
a special trial preceding the trial-in-chief on the issue of guilt, a procedure which is bound to interfere with any scientific examination of the defendant. It is no more fitting that a psychiatric examination be made in open court and under rules of evidence than that a patient with possible diphtheria be brought into court on a stretcher and examined subject to the eagle eye of judge or jury, and the non-medical majesty of the law.

That the provision for such routine mental examination as is provided in Massachusetts ought to result in the accumulation of valuable scientific data on the subject of the mental make-up of the recidivist is apparent. But more immediate and practical results are to be expected from such a law. In the first place, the mentally unsound can be spared the ordeal of a trial. In the second, the state and its officers will be saved the great expenditure of time, effort and money involved in the prosecution of those who ought not to be tried, in cases where the findings of the unbiased experts, appointed by a perfectly neutral agency before trial, are accepted by the defendant's counsel, the district attorney, and the court, as a working basis for the disposition of the case without formal trial, by nol-prossing or filing the case and committing the defendant to a hospital for the mentally ill. At any rate, even in the rare case where a trial is resorted to after the alienists report the existence of a mentally abnormal condition, these reports by neutral psychiatrists dispose of the need or excuse for a long-drawn trial with opposing experts. In its place is the mere formality of a brief hearing, say from ten minutes to an hour, resorted to merely for the purpose of making the record complete by entering a verdict which the court, upon the agreement of all concerned, instructs the jury to bring in. The actual practice, when the experts report a person as having a definite psychosis, varies in different parts of the state. One district attorney may prefer to have the case filed or to nol. pros. it, so long as the defendant is committed to a hospital where he can do no further harm and can receive protection and treatment. Other prosecutors prefer to have the record of a verdict of "not guilty by reason of insanity." The result in both types of procedure is to commit the defendant to a hospital until such time as he has sufficiently recovered no longer to be a public menace.

Even in the vexing "borderline cases" of "constitutional psychopathic inferiority," where either of the parties prefers to continue with an elaborate trial and conflicting alienists, in spite of the report of the neutral experts of the Department of Mental Diseases, these unbiased reports will serve to impress upon the district attorneys and judges that in such cases as mental defectiveness, "constitutional psychopathic inferiority," and the like, defendants should at best be regarded as only partially respon- 
sible for their conduct. We may hope, as a result, for a more humane, uniform and sensible disposition of the puzzling borderline cases of the "semi-responsible" than is now characteristic of most jurisdictions. Indeed, the opportunity of the examiners to educate judges and prosecutors in the "psychiatric point of view," by means of complete, clearly-presented, convincing reports, cannot be over-emphasized.

If no mental condition is found and the defendant does not admit his guilt, a trial on the merits is of course had as in other cases.

Another great advantage of this law over legislation in other states is that persons dangerous to the general security because of some latent or developing mental defect or disorder, whose condition is frequently not detected until after they have committed some shocking crime, can be discovered early in their delinquent careers, and the public can thus be protected before such offenders have had further opportunity to injure society. This is especially true in the case of the so-called "defective delinquent" group who, in Massachusetts, may be committed to a special institution for such offenders, there to be held until such time as they can with safety be discharged, $-\mathbf{a}$ wholly indeterminate period which may even amount to life incarceration.

\section{MASSACHUSETTS LAW IN ACTION}

Some of the results of a study of the cases reported for mental examination up to and including October 15, 1926, a period of some five years, may now be examined.

Analysis of cases psychiatrically eramined and those not eiamined. The number of cases reported by clerks of courts to the Department of Mental Diseases for examination up to October 15 and not pending at the time was three hundred sixty-seren. Of this number, seventy-two were not examined for the following reasons: almost half had been released on bail and could not be found when the examiners called at the place of detention; several cases had been nol-prossed or discharged before examination; and in about one-fifth of the cases the court had imposed sentence before examination by the experts. Eight of those reported for examination refused to be questioned, on advice of counsel, all but one of these having been indicted for murder in the first degree. These seven constituted, however, a surprisingly small percentage of the total number (173) of indictments for a capital offense. In other words, counsel for defendants are on the whole very co-operative. Indeed, in one case, after the department's psychiatrists had reported that defendant had dementia praecox, a definite psychosis, the defendant's lawyer, who might have had a good "defense of insanity," himself 
seriously questioned the diagnosis until convinced, after several further conversations with his client, that the latter was mentally ill.

Several defendants were reported for mental examination but as they did not fall within the provisions of the law they were not examined. Of these a few did not come within the law because they were indicted for manslaughter or second degree murder and were therefore not in the class of "capital offenders" provided for in the act, and several because their previous records, so far as could be ascertained, involved only misdemeanors.

On examining the history of one offender (taken at random) who was not mentally examined because out on bail, the following record was disclosed:

$$
\text { Offense Date Disposition }
$$

1. Attempted larceny and as- 1905 Case filed. sault and battery.

2. Breaking and entering, 1910 Pleaded guilty. and larceny.

3. Breaking and entering. 1911 Probation-Defaulted.

4. Trespass. 1911 Fined \$5.

5. Breaking and entering, 1911 Probation granted.

6. Larceny.

1911 Five years in Mass. Reformatory ; releạsed in 13 months.

7. Burglary (Michigan). 1913 Six months to 15 years in Reformatory.Released in 17 months.

8. Disturbing public assem- 1916 Fined $\$ 10$. bly.

9. Robbery.

1916 Four years, House of Correction; Transferred, Mass. Ref'ty, in two months and released in 18 months.

10. Assault and battery.

1919 Fined $\$ 10$.

11. Conspiracy.

1920 Filed.

12. Larceny.

1920 Six months, county jail.

13. Assault and battery.

1920 Filed.

14. Pres. game. 1921 Filed.

15. ? ?

16. Attempt to escape from House of Correction.

17. Larceny.

1921 Three months, House of Correction.

1922 Not examined because "out on bail and court does not know his whereabouts."

Since then the following offenses have been found recorded against him: 
18. Larceny.

19. Disturbing the peace.

20. Drunk.

21. Drunk.
1922 Six months, House of Correction.

1922 Fined \$5.

1922 Fined $\$ 5$.

1926 Rieleased.

This record is probably incomplete, as it represents only those offenses to be found in the Massachusetts files and there is no guaranty that the files, though in some respects the best of any state in the Union, are complete as to cases running back for a number of years or offenses committed in other jurisdictions. It shows clearly the utter futility of the usual judicial procedure and penal treatment in such cases, and indicates vividly the continuing social menace presented by this type of offender. Yet, as stated, this man could not be examined under the Massachusetts law, not because he did not fall within its provisions but because he had been released on bail and could not be found. It is to be hoped that judges will soon see to it that such offenders are not turned back to the community on bail before they have been mentally examined. $\mathrm{s}$ Indeed, the whole subject of the actual operation of the judicial function of releasing on bail needs careful study with a view to malking the practice more rational.

Crimes of those mentally eramined. Against the 295 accused persons examined by the experts, there were 173 indictments for capital offenses and six for second-degree nurder or manslaughter (these six having been examined berore it was established that the law did not strictly apply to them). Nineteen indictments against those examined were for sex offenses, fifty-two for larceny, forty-six for burglary, sixteen for robbery, fourteen

8 The recently enacted chapter 320, $\$ 1,2$, Miass. Acts 1026, should remedy this situation in part. Section 1 provides that "Before the amount of bail of a prisoner charged with an offense punishable by impriconment for more than one year is fixed in court, the court shall obtain from its probation officer all available information relative to prior criminal prosecutions, if any, of the prisoner and to the disposition of each such prosecution." Section 2 provides in part as follows: "In addition to the other duties imposed upon him, each probation officer shall, as the court may direct, inquire into the nature of every criminal case brought before the court under the appointment of which he acts, and inform the court, so far as is possible, whether the defendant has previously been convicted of crime and in the case of a criminal prosecution before said court charging a person with an offense punishable by imprisonment for more than one year the probation officer shall in any event present to the court such information as the commission on probation has in its possession relative to prior criminal prosecutions, if any, of such person and to the disposition of each such prosecution, and all other available information relative thereto, before such person is admitted to bail in court and also before disposition of the case against him by sentence, or placing on file or probation."

It is generally conceded that the records of the Massachusetts Probation Commission are the most complete of any in the United States. 
for dangerous assault with intent to rob or kill and fifteen for various other offenses. ${ }^{\circ}$

Crimes of those not mentally examined. Of the seventy-two not examined there were fifteen indictments for capital offenses, five for second-degree murder or manslaughter (these not coming within the law), five for sex offenses, twenty-three for larceny, twenty for burglary, three for robbery, three for assault with intent to kill or rob, and six for various other offenses.

Mental condition of those examined. Surveying now the reports on mental examination of the 295 accused persons examined, we find that there was reported "insanity" (i.e. a definite major psychosis) in twenty-six cases, psychopathic personality in eleven, mental deficiency or defective delinquency in twentyfive, there thus being reported some abnormal mental condition in sixty-two cases or about twenty-one per cent of those examined. Seven more were recommended for observation in a hospital for mentally ill. This left 226 cases or seventy-six per cent in which no evidences of mental deviation from the normal were discovered. If one were to assume that the percentage of cases in which a noticeable mental condition existed was the same in those not examined as in those examined, then about one-fifth of the seventy-two cases not mentally examined for one reason or another, or fourteen, probably had some abnormal mental condition.

With the exception of one, those reported "insane" were upon such finding committed by the courts either to the hospital for the criminal insane or to some other state hospital.

In the twenty-six cases in which the experts reported a definite psychosis their diagnosis has in general terms been borne out by subsequent observation in the hospitals to which defendants were committed.

Twenty-five cases were diagnosed as mental deficients or defective delinquents. The latter designation is, however, more of a legal-psychological than a psychiatric one; since the defective delinquent law of Massachusetts provides for the commitment, upon the certificates of two qualified physicians, for an indeterminate period to the special institution for defective delinquents, of certain mentally deficient offenders who have had a consistent career of criminality or have proved too troublesome a disciplinary problem to be coped with in the ordinary penal institution, school for feeble-minded or hospital for the mentally ill.10

Among those found to be mentally deficient there were a

9 The total of these figures (341) does not tally with the total number of accused persons examined (295) as a number of defendants were indicted for more than one crime. The same is true of those not examined (72) their total of crimes having been 80 . Thus a total of 367 offenders who were reported for examination were indicted for 421 offenses.

101 Mass. Gen. Laws (1921) c. 123, §§ 113-116. 
number of rapists and those who committed unnatural sexual acts, murderers, and dangerous robbers and burglars. How did the courts dispose of these mentally deficient offenders?

Disposition of mental defectives. Six of those found to be mentally deficient were wisely committed by the courts for an indeterminate period to the special institution for defective delinquents. In a number of cases, however, where the experts declared defendants to be mentally defective, the courts did not commit them under the defective-delinquent law, but disposed of them in the traditional manner. Thus, to cite some examples, one originally indicted for murder but tried for manslaughter received one year in the house of correction. Several were sentenced for indeterminate periods ranging from five-seven years to twenty-twenty-six years in the state prison. For assault with intent to rape, one such mentally defective defendant, aged eighteen, received five to seven years, which means he will shortly be released probably to continue his dangerous acts, if one may judge from his past performances as indicated by the following record:

He had trouble in school after the fifth grade; at twelve he was arrested and put on probation; soon thereafter he was committed to a state industrial school. Shortly after his discharge therefrom he was committed to the Miassachusetts Reformatory, for sodomy. On release, he enlisted in the Navy but was shortly given a dishonorable discharge. $\mathrm{He}$ admits the practice of pederasty since an early age.

Another defective delinquent, indicted for murder and convicted of manslaughter, received from five to ten years in prison; still another, convicted of "carnal abuse of female child," and of incest, received from seven to ten years in prison. That this man will be a menace upon his discharge is indicated by the following extracts from the summary report of the experts:

"When at home he was usually intoxicated, and had a revolver with which he terrorized his wife and children. His abusive conduct was known to the neighborhood. . . He has always been unduly sexed. . . . He is stupid in appearance and conduct, understands only very simple questions, and exhibits a typical feebleminded attitude. On a psychometric examination his highest performance is at an eight year level. . . . He is classified as a . . . low grade moron."

To punish a feebleminded person for a few years only to return him again to society to continue his anti-social activities is a mode of legal treatment which the progress of science must eventually overthrow. From a social point of view, incarceration of mental defectives for a more or less definite term in 
prison certainly does not constitute a solution of the recurring problems they present.

The cases against two mental defectives were "filed." These were an indictment against one for breaking and entering in the night-time and larceny, and two successive indictments against

- the other, one being for forgery and uttering, the second for breaking and entering at night and larceny. It would be a good practice to have judges clearly set forth their reasons, in writing, for placing cases on file, by way of final disposition, such signed statement to constitute part of the record.

Disposition of "psychopathic personalities." The diagnosis in eleven cases was "psychopathic personality" or "constitutional psychopathic inferiority." It is noteworthy that this condition was found in only eleven out of the 295 cases examined. This is an interesting contradiction of those who insist that if psychiatrists had more to do with the criminal law, they would find almost all criminals irresponsible, throwing them at least into the category "constitutional psychopathic inferiority," if they could establish no definite major psychosis. Two psychopaths were convicted of first degree murder and appealed; and, pending such appeal, we will not comment on them. In one 11 of the eleven, a capital case, the experts called the attention of the court and the district attorney to the defendant's condition of "border-line" mental disorder, and these officials agreed that, while not absolutely irresponsible for his criminal acts, such an individual should nevertheless be considered as only partially responsible. He was, therefore, given a life sentence. This illustrates the kind of legitimate influence that can be exerted by unbiased experts to educate judges and prosecutors and to lessen the rigor of the law in cases such as this, wherein an inflamed public opinion demanded the death penalty $-a$ fact that members of the jury conveyed to the district attorney in the case after their discharge, when he had agreed to accept a plea of second degree murder on the recommendation of the experts. Here a wise social disposition was made of a type of case that has been the source of much medico-legal discussion, the problem of the "partially-responsible." ${ }^{2}$ The prisoner was placed for the rest of his life where he can do no further harm; at the same time his mental condition and limited responsibility were considered and balanced against the legal demand of the extreme penalty.

It is cases of this type and their possible orderly, speedy and inexpensive disposition where a piece of legislation of the kind

\footnotetext{
11 Recently a similar case was disposed of in a like manner.

12 The whole problem of the so-called "semi-responsible" from the judicial and psychiatric, as well as ethical, points of view is exceedingly complicated. See GLUECK, op. cit. supra note 2.
} 
we are considering exists, that suggests that if a law like the Massachusetts statute had existed in Illinois when the LeopoldLoeb case arose, those defendants might have been disposed of as they finally were, but without much of the long-drawn proceedings, the rancor and misunderstanding and the needless expense of the hearing in mitigation. Had such legislation existed, it seems highly probable that counsel for the youths would have readily agreed to their examination by experts appointed, not by the prosecution, nor by the defense, nor even by the court, but by the state department of mental diseases, a body neither consciously nor unconsciously connected with, nor influenced by, the administration of criminal justice in any particular case at bar, a state agency engaged merely in the scientific examination of all offenders regardless of age, means, or other condition. The report of such experts, available to all parties concerned, might have been the basis for the disposition of the case then and there, if the prosecution had been willing, in the light of the report from an entirely neutral source, to acquiesce in a sentence of life imprisonment; or; in the event the prosecutor was unwilling to agree to such disposal of the case on the basis of the report, the report would at least have formed the basis for the next step in the proceedings, and might have aided the court in the performance of its difficult task.

Some of the other cases of psychopathic personality found by the Massachusetts experts were not disposed of quite so wisely, from a broad social point of view, as was the case discussed above. One psychopathic delinquent received one $y / \mathrm{car}$ in the house of correction on the following report of the experts:

"Age twenty-nine; divorced. . . . Father deserted when (patient) three years of age. Became a state ward; attended school to the eighth grade.

"At eleven years sent to Lyman School as a stubborn child, remaining for three years; then transferred to Concord Reformatory, for larceny, where he stayed fourteen months; later committed to state prison, for burglary and larceny, where he served four years; from 1908 to 1911 was in the U. S. Army; was arrested as a deserter and served a sentence in Leavenworth. He also served a year' and one-half at Blackwell's Island, a sentence at Sing Sing, and three months at Holmesburg, Pennsylvania.

"Has always been of nervous make-up, troubled with insomnia, an occasional user of morphine. Eleven days prior to arrest was paroled from state prison.

"Mental examination shows an average intelligence, no hallucinations or delusions or gross evidence of insanity. Patient shows marked emotional instability, threatening suicide in case he is convicted again.

"From his history and from our examination, we are of the opinion that his emotional instability is pathological. While ve believe this man to be neither insane nol feebleminded in a legal 
sense, we believe his career to be adequately explained by a disordered personality, ordinarily classified as constitutional psychopathic state."

This is the type of case with which our socio-legal engineering has as yet utterly failed to cope. Every judge who had anything to do with the sentencing of this person, and who read the results of previous brief sentences, must have felt how hopelessly inadequate are the legal means at our command today for making a wise social disposition of such cases. Under the law, in the face of this report-and realizing, no doubt, what a ridiculous palliative he was prescribing--the judge was forced to give this man a brief sentence.

Following up the subsequent history of this prisoner, whom the court was forced to dispose of in the archaic manner provided for by modern law, we find, as might have been prognosticated, the following record:

Five months after his sentence to house of correction, he was transferred to the prison camp and hospital, escaping therefrom the same day. When next heard from, in May, 1924, he had been sentenced for burglary in London, England, to five years servitude and deportation at the end of that period.

We may confidently predict a continuation of his anti-social career on his discharge.

Judges alone cannot be blamed if such laws as the Massachusetts act for the routine mental examination of certain classes of offenders cannot fully achieve the ends for which they were designed. The fault lies in the legislative prescription, in advance, of definite, brief sentences, under the easily-pierced disguise of "indeterminate sentences," and in the failure to provide a special penal-correctional institution for psychopathic delinquents. ${ }^{13}$

We cite the record of another psychopath as illustrative of the ineffectiveness of present methods of disposition of such cases:

\begin{tabular}{llll} 
& Offense & Date & \multicolumn{1}{c}{ Disposition } \\
1. Larceny, bicycle. & 1904 & Probation six months. \\
2. Habitual truant. & 1905 & Not guilty. \\
3. Larceny. & 1905 & Not guilty. \\
4. Delinquency (Larceny). & 1907 Probation. \\
\hline
\end{tabular}

${ }^{13}$ Such an institution has long been urged as a practical necessity in Massachusetts. It was recommended by Dr. Bernard Glueck, in his article Concerning Prisoners (1918) 2 Mental HygIene, 177. Its need has been recognized by progressive penologists. Psychopathic offenders present disciplinary and other problems in a penal institution that seriously affect its efficiency with more normal offenders. Massachusetts has taken the lead in recently establishing a separate institution for female defective delinquents in addition to the existing one for male defective delinquents, and it is hoped that special institutions for psychopathic offenders will follow. 

5. Desertion and impersonat- ing officer.
6. Grand larceny.
7. Desertion.
8. Breaking and Entering,
and Larceny.

9. Breaking and Entering.
1918 Five years in the U. S. disciplinary Barracks.

1919 Disposition unknown.

1920 Two years in U. S. disciplinary Barraclis.

1922

Iiass. Reformatory, 5 years; released in 15 months.

1925 Five to seven years in prison.

This man was of good education and intelligence. In between offenses he had the opportunity to marry, be divorced, and remarry. He had a history of convulsions occurring between ages of 21 and 23 and diagnosed as epileptic, in connection with which there were unconscious periods. Later he had been committed to a hospital for observation, the result being a diagnosis of "psychopathic personality." The experts of the Department also diagnosed him as a psychopathic personality. He will doubtless continue his anti-social activities on his discharge.

Another psychopath convicted of breaking and entering and larceny was in 1923 sentenced to the state reformatory on a fiveyear "indeterminate" sentence, released in sixteen months on parole, and is at present "wanted" for violation of parole.

Anyone who has studied the anti-social careers of psychopaths must admit that these cases are quite typical. In all such cases and in most of the cases of defective offenders, the best of laws can do but little until society, through its machinery for legal regulation of the social order, decides to take the radical step of incarcerating such unstable offenders for a wholly indeterminate period, its actual length to depend not upon the wishes of the trial judge-who has had little opportunity, if any, to study the prior history of the offender and his development under penal and correctional treatment-but on the judgment, either of psychiatric and social workers attached to and informing the court, or of highly trained prison officials who can study the behavior of the offender over a long period of time, and who it would seem are logically the ones to say when such offenders can reasonably be expected to make good in society.

Criticism of the law. A brief criticism of the law is not out of place by way of conclusion. First, it applies, under the first category, only to capital offenders, thus making no provision for second-degree murderers or for those indicted for manslaughter. Under the second category-consisting of persons lnown to have been indicted for any other offense more than once-those previously indicted but once cannot be examined. In the third category-of persons previously convicted of a fclony-criminals 
with long records of misdemeanors are not included. ${ }^{14}$ It is well known that the most promising material for the study of recidivism is among those who for various causes have had a long career as petty offenders. The line between misdemeanor and felony is, after all, artificial, when the distinction is considered from the psychiatric point of view; and the relationship of the mental condition to the illegal act is equally important in misdemeanor and felony.

Secondly, the reporting of the cases depends upon the clerlks of the courts, who are not compelled to make such reports if they do not, in the language of the statute, know of the previous records of offenders. Thus clerks can always claim, by way of excuse for failure to report cases, that they had not the knowledge of prior offenses. Obviously, out of the large number of cases that have come up since the law went into effect, more than 367 should have been reported for examination. That failure to report for examination all the cases falling within the provisions of the law resulted in useless expenditure of time and money and in the unnecessary subjection of at least some who were mentally -ill to the ordeal of a trial, is illustrated by this fact: A careful check-up on those persons sentenced to the state prison during the operation of the law, who had not been reported for mental examination before trial, discloses that at least five convicts among those who had to be transferred from prison to mental hospitals because they were found to be suffering from mental disease, developed symptoms within such a brief period after their sentence to prison as to force us to the conclusion that a mental examination before trial would have disclosed the disease and probably have rendered the trial and imprisonment unnecessary. These prisoners, instead of being committed directly to the hospital where they belonged, had to pass through the wasteful, roundabout route of criminal court and prison to their ultimate destination.

In view of the foregoing, the law should be amended to place upon the probation officer the duty of informing the clerk as to the prior record of offenders, so that clerks cannot shirk their responsibility by saying they had no such knowledge. Indeed, with the existence of a state-wide record system there is no excuse for clerks of court not being able to furnish judges with prior records of offenders; such records being basic to any rational disposal of cases.

${ }^{14}$ This gap is, however, now being effectively filled by another piece of legislation and machinery in which Massachusetts has again taken the lead, namely, the law of Sept. 1, 1924 (Mass Acts 1924, c. 309) providing for the psychiatric and social investigation of inmates in the jails and houses of correction who are serving a sentence of thirty days or over (except for non-payment of fine) and those who have a prior record of commitment to any penal institution. 
Finally, some of the cases we have discussed indicate that it will be some time before trial judges co-ordinatc their disposition of cases with the experts' reports on such cases. The question, in other words, is the fundamental one of co-operative interrelation of all the agencies that deal with the offender from the moment of his arrest to the time of his ultimate return to society. This is probably the most fundamental problem to be solved in the practical field of the administration of criminal justice, and is perhaps a major reason for the much-vaunted superiority of European lawr-enforcement machinery:

In spite of these patent defects of the MIassachusetts law, however, it should be reiterated that this provision for the routine mental examination of persons accused of crime, even as it stands today, is far in advance of any similar legislation in any state of the Union. Its efficient principle is to reduce to a minimum the trial of persons who, because of mental abnormality, can more wisely, cheaply and speedily be disposed of without a formal trial. It eliminates the objectionable feature common to all other state legislation on the subject-namely, the leaving of the mental examination of offenders to chance or caprice instead of, as in Massachusetts, making it a prescribcd, scicntific, unbiased procedure in every case of certain classes. It serves as a reliable aid to the prosecutor in advising him as to which cases it would be useless, or at least needlessly expensive, to try rather than to commit forthwith. The practice generally is to place on file a case in which the experts of the Department of Miental Diseases have reported a serious mental condition, and to have the defendant committed to a hospital. If he ever recovers, he may of course, theoretically, again be placed on trial. Usually, however, the condition of one reported mentally ill is such as to require long treatment and his more or less permanent incarceration, for the good of himself and the safety of the community. It is true that occasionally a prosecutor may insist upon a trial even in a case where the Department's unbiased reports finds the defendant suffering from mental disease; but in such an event this is usually done, as we have said, only for the purpose of closing the record, the "trial" being a mere brief formality. In such cases the jury is instructed to find the defendant "not guilty by reason of insanity," the defendant is straightway committed to an appropriate hospital, and the case is closed. Thus another advantage of the Massachusetts law is that it makes for a much better understanding than has hitherto existed between practical workers in the legal and medical professions as to the perplexing question of the criminal irresponsibility of the mentally ill.

In addition the law has brought about a marked diminution in the use of conflicting alienists in insanity cases; for the unbiased status of the experts who make the examinations-they being 
employed not by either side nor even by the court, but by the State Department of Mental Diseases-has put them at a distinct advantage over partisan experts. But perhaps the most important though least obvious rôle which is being played by the unique Massachusetts law is that of harbinger of a new criminal procedure toward which, it would seem, the advance of criminological knowledge will gradually force us; namely, the basing of the offender's treatment in all cases-both as to length and typenot on the mechanical dosages of punishment prescribed by legislatures in advance, but on the rational exercise of judicial discretion enlightened by the scientific reports of psychiatric, psychological and sociological experts who should form an indispensable adjunct of the criminal courts of tomorrow. 